\title{
Amblyopia (lazy eye) in children
}

\author{
Agnes M.F. Wong MD PhD
}

\begin{abstract}
Amblyopia is a unilateral or, less commonly, bilateral reduction of best-corrected visual acuity in an otherwise normal eye
\end{abstract}

Amblyopia is clinically defined as a visual acuity of $20 / 40$ or worse and a difference in vision between the eyes of two or more lines on a vision chart, with no apparent structural abnormality. ${ }^{1}$ The condition affects about $3 \%$ of the general population. Incompletely treated or untreated amblyopia can result in lifelong visual impairment. ${ }^{1}$

Treatment includes eyeglasses and penalizing the strong eye

Treatment of strabismic or anisometropic amblyopia consists of correcting the underlying condition or deficit in addition to forcing the use of the amblyopic eye, either by patching or using pharmacologic agents to penalize the strong eye. ${ }^{1}$ Deprivational amblyopia is treated by removing the opacity as soon as possible, followed by penalizing the strong eye to encourage use of the amblyopic eye. ${ }^{1}$

CMAJ invites submissions to "Five things to know about ..." Submit manuscripts online at http://mc.manuscriptcentral .com/cmaj

\section{Amblyopia is caused by abnormal visual experience early in life}

The most common causes of amblyopia are refractive errors or strabismus (squint), but the condition can also be caused by visual deprivation. ${ }^{.}$Competitive or inhibitory interaction between cortical neurons carrying inputs from the eyes leads to reduced responsiveness to input from the weak eye. ${ }^{2}$ The onset of strabismus before three years of age and high degrees of misalignment are associated with increased risk and severity of amblyopia. ${ }^{1}$ Early onset and high levels of anisometropia (i.e., unequal refractive errors) or astigmatism have outcomes similar to those of strabismus. ${ }^{1}$ Substantial media opacities (e.g., cataract) and conditions that occlude the visual axis (e.g., ptosis) can also result in amblyopia. ${ }^{1}$

\section{Vision screening in children is impor- tant for the prevention and early treatment of amblyopia}

For infants and toddlers, fixation and tracking behaviour should be observed. ${ }^{3}$ Visual acuity tests should be performed in older children, using the HOTV chart or LEA symbols for children aged three to five years, and the Sloan or Snellen chart for children aged six years and older. $^{3}$ Recommendations of the Canadian Paediatric Society for vision screening in children are listed in Appendix 1 (available at www.cmaj.ca/lookup/suppl /doi:10.1503/cmaj.130666/-/DC1). ${ }^{3}$

\section{References}

1. American Academy of Ophthalmology Pediatric Ophthalmology/Strabismus PPP Panel, Hoskins Center for Quality Eye Care. Amblyopia PPP. San Francisco (CA): American Academy of Opthamology; 2012. Available: http://one.aao.org/preferred-practicepattern/amblyopia-ppp--september-2012 (accessed 2013 Oct. 28).

2. Wong AM. Implications of interocular suppression in the treatment of amblyopia. JAAPOS 2011;15:417-8

3. Vision screening in infants, children and youth. Paediatr Child Health 2009;14:246-51.
Novel and potentially useful treatments for amblyopia are currently under investigation

Various therapies (e.g., drugs, acupuncture and video games) have been proposed for the treatment of amblyopia; however, they are not currently recommended to replace or use as an adjunct to patching or penalization therapy. 1,2

\section{Competing interests: None declared.}

This article has been peer reviewed.

Affiliations: Department of Ophthalmology and Vision Sciences, University of Toronto, and The Hospital For Sick Children, Toronto, Ont.

Correspondence to: Agnes Wong, agnes.wong @utoronto.ca

CMAJ 2014. DOI:10.1503/cmaj.130666 